\title{
12-Hydroxyjasmonic Acid Glucoside Causes Leaf- Folding of Samanea Saman Through the ROS Accumulation
}

Minoru Ueda ( $\nabla$ minoru.ueda.d2@tohoku.ac.jp )

Tohoku University

Gangqiang Yang

Yantai University

Yasuhiro Ishimaru

Tohoku University

Shunji Hoshino

Tohoku University

Yuki Muraoka

Tohoku University

Nobuyuki Uozumi

Tohoku University

\section{Research Article}

Keywords: nyctinasty, jasmonate, jasmonic acid glucoside, potassium channel, reactive oxygen species, Samanea saman

Posted Date: February 22nd, 2022

DOI: https://doi.org/10.21203/rs.3.rs-1336768/v1

License: (c) (1) This work is licensed under a Creative Commons Attribution 4.0 International License.

Read Full License 


\section{Abstract}

Foliar nyctinasty, the circadian rhythmic movement of plants, is common among leguminous plants and has been widely studied since the era of Charles Darwin. Biological studies on nyctinasty have been conducted by using Samanea saman as a standard plant. By using S. saman, it is revealed that the circadian rhythmic turgor change in the motor cell is responsible for the foliar nyctinasty: the circadian rhythmic potassium flux from/in motor cell triggers shrinking/swelling of the cell to cause nyctinastic leaf-folding/opening movement of $S$. saman. Recently, 12-hydroxyjasmonic acid glucoside (JAG) was identified as an endogenous chemical factor causing the leaf-folding of $S$. saman. In addition, SPORK2 was identified as an outward-rectifying potassium channel causing leaf-movement of the same plant. However, molecular mechanism linking between JAG and SPORK2 remains elusive.

Here, we report that JAG induces leaf-folding through accumulation of reactive oxygen species (ROS) in the extensor motor cells of $S$. saman, which occurs independently of plant hormone signaling. SPORK2 is indispensable through the JAG-triggered shrinkage of the motor cell. This is the first report on JAG, believed to be an inactivated/storage derivative of JA, acting as a bioactive metabolite in plant.

\section{Introduction}

Circadian rhythmic leaf-folding, called nyctinasty, is a widely-observed, a physiological behavior of leguminous plants ${ }^{1,2}$, which open their leaves in the morning and fold them in the evening. The rhythm of this phenomenon is not affected by environmental conditions and occurs even under continuous light/dark conditions. The pulvinus, a specialized organ located in the base of legume leaflets, bends and straightens according to the circadian rhythm ${ }^{3}$. Unequal volume changes of the motor cells in adaxial/abaxial side of pulvinus cause the leaf movement.

The earliest record of this phenomenon dates back to the reign of Alexander the Great in 400 B.C ${ }^{4}$. Later, in the 18th century, the first discovery of a biological clock was reported in the context of the nyctinastic leaf-movement of Mimosa pudica ${ }^{5}$. In his later years, Charles Darwin devoted himself to the study of plants, and at the end of the 19th century published a paper entitled "The Power of Movement in Plants," wherein he summarized his extensive observations of plant movement ${ }^{6}$. Samanea saman was established as a standard plant for the study of nyctinasty in $1958^{7,8}$. However, focused researches into the physiological basis for plant nyctinasty were performed until the $1970 \mathrm{~s}-1990 \mathrm{~s}^{9}$. During this period, a number of landmark studies of Samanea saman (Fig. 1) were reported, such as those on potassium flux and leaf movement ${ }^{10,11}$, relationship between leaf movement and the biological clock ${ }^{12,13}$, the identification of motor cell as the primarily cause of leaf-movements ${ }^{14,15}$, electrophysiological studies on putative ion channels ${ }^{16-19}$ and aquaporin ${ }^{20}$, and the effects of red/blue light ${ }^{21,22}$.

Previously, we reported that leaf-movements in leguminous plants are controlled by endogenous chemical factors ${ }^{23-25}$. We focused our attention on 12-O-b-D-glucopyranosyl-jasmonic acid, also referred to as jasmonic acid glucoside (JAG, or also called LCF in ref 21), a leaf-folding substance of $S$. saman 
(Fig. 1) ${ }^{26}$, and found that the JAG binds to extensor motor cells located in the pulvinus on the adaxial side of the leaf through the putative target, membrane target protein of jasmonate glucoside (MTJG) ${ }^{27}$. JAG caused shrinking of the protoplast prepared from Samanea adaxial motor cells (extensor cells) and did not affect that of abaxial motor cells (flexor cells) ${ }^{26}$. It is possible that JAG-induced shrinking occurs either in a COI1-independent manner or in a COI1-dependent manner because Samanea has a modified COI1-JAZ that also binds to JAG. In addition, we identified SPORK2, a potassium channel responsible for the leaf-movement of $S$. saman ${ }^{28,29}$. However, the mechanistic basis for the induction of $\mathrm{K}^{+}$release by activation of the potassium channel by JAG remains elusive. Here, we report that JAG induces the accumulation of reactive oxygen species (ROS) in the adaxial motor cells of $S$. saman to induce cell shrinking. JAG-induced shrinking of adaxial cells occurs independently of the plant hormones jasmonic acid (JA) and abscisic acid (ABA), which are also known to induces shrinking of guard cells. This finding will pave the way to a complete understanding of the molecular mechanism of JAG-triggered nyctinastic leaf-closing in S. saman.

\section{Results}

\section{JAG-induced accumulation of second messengers in motor cells}

The shrinking of stomatal guard cells during stomatal closure is well known in the study of cell-shrinking in plants, and a plethora of molecules involved in the ABA-induced stomatal cell shrinking have been identified ${ }^{30,31}$. In particular, reactive oxygen species (ROS) and calcium ions are known to play an important role as second messengers ${ }^{32,33}$. ROS are effective signaling molecules that can induce guard cell shrinkage in both methyl jasmonate (MeJA)- and ABA-induced stomatal closure ${ }^{34}$. We compared the effect of JAG with plant hormones ABA/JA both in Samanea extensor motor cells and Arabidopsis guard cells. It is also possible that 12-OH-JA, the hydrolyzed product and a biosynthetic precursor of JAG, might function as the bioactive form of JAG. However, in our previous report, we confirmed that 12-OH-JA did not induce shrinkage of Samanea motor cells ${ }^{26}$, so $12-\mathrm{OH}-\mathrm{JA}$ was excluded from the experiments in this paper. We examined whether JAG affects the accumulation of ROS and calcium ions in the protoplasts of Samanea motor cells using small molecular indicators of ROS- and $\mathrm{Ca}$, because no genetic transfection, such as the introduction of GFP or aequorin, can be achieved in $S$. saman (data not shown).

Protoplasts of Arabidopsis guard cells and Samanea motor cells were prepared as previously reported. Intracellular ROS- accumulation in these protoplasts was monitored using the fluorescent dye 2', 7'dichlorofluorescin diacetate $\left(\mathrm{H}_{2}\right.$ DCF-DA), which is widely used as a ROS-indicator in guard cells ${ }^{35,36}$. Significant ROS accumulation was triggered in the guard cells of $A$. thaliana by $10 \mu \mathrm{M} A B A$, consistent with previous reports, Fig. $2 A{ }^{35,36}$. No ROS accumulation was observed in guard cells of $A$. thaliana treated with $100 \mu \mathrm{M}$ JAG (Figs. 2A and 2C). In contrast, significant ROS accumulation was triggered in protoplasts isolated from Samanea extensor motor cells by $100 \mu \mathrm{M}$ JAG, whereas $100 \mu \mathrm{M}$ ABA had no 
distinct effect on ROS generation in motor cells (Figs. 2B and 2D). In addition, JAG-induced ROS accumulation was not observed in Samanea flexor motor cells, wherein JAG cannot induce cell shrinking (Fig. 3B and $3 \mathrm{~F})^{26}$. It was concluded that JAG triggered ROS accumulation in extensor motor cell protoplasts, whereas ABA triggered ROS accumulation in guard cells, and that the responses to JAG and ABA of Arabidopsis and Samanea protoplasts were very different. This result suggests the modes of actions of JAG and ABA to be different, and that responses to endogenous chemicals in Arabidopsis guard cells and Samanea motor cells are different.

MeJA is widely used to trigger JA signaling in plants ${ }^{37}$. MeJA-like ABA also induces stomatal closure 34,38 . However, JA cannot induce shrinkage of extensor motor cells ${ }^{26}$. We examined the effect of MeJA on ROS accumulation in extensor motor cells. Treatment with $10 \mu \mathrm{M} \mathrm{MeJA}$ triggered ROS accumulation in Arabidopsis guard cells (Figs. 2A and 2C), a result consistent with previous reports ${ }^{35,36}$. In extensor motor cell protoplasts, JAG treatment triggered ROS accumulation, whereas $100 \mu \mathrm{M}$ MeJA treatment did not affect the ROS accumulation within $15 \mathrm{~min}$ (Figs. 2B and 2D). These results are consistent with the previous finding that JAG is an inactivated derivative of JA and cannot induce JA signaling ${ }^{39}$. These results suggested that JAG-triggered ROS accumulation is independent of JA signaling. Thus, we further focused on the JAG-induced accumulation of ROS in the Samanea motor cells.

\section{JAG-induced ROS accumulation in the cytosol triggers shrinkage of extensor motor cell protoplasts}

Recent studies have shown that ROS accumulates in different subcellular components by different mechanisms ${ }^{40}$. In general, chloroplasts are the largest ROS producers in plants, especially in periods of light. In contrast, mitochondria produce most ROS in the dark and in non-green tissues ${ }^{40}$. JAG triggered ROS accumulation in the extensor motor cell protoplasts of $S$. saman. Understanding the subcellular distribution of accumulated ROS will provide insight into its mechanisms of action.

We analyzed the subcellular distribution of JAG-induced ROS using double staining experiments of extensor motor cell protoplasts with $\mathrm{H}_{2}$ DCF-DA and MitoTracker Red CMXRos. Chloroplasts were identified by autofluorescence. The background DCF signal in the Mock treatment was strongly colocalized with chloroplasts and mitochondria (Figure S1). However, JAG treatment caused a remarkable increase in the DCF signal in the cytosol (Figure S1). This result demonstrated that JAGtriggered ROS accumulation occurs in the cytosol.

Next, we examined whether JAG simultaneously induced ROS accumulation and cell shrinkage in Samanea extensor motor cell protoplasts. Cytosolic ROS accumulation and cell shrinkage were recorded simultaneously for protoplasts isolated from Samanea extensor/flexor motor cells prepared from the adaxial/abaxial side of the pulvinus, respectively (Fig. 3). However, although JAG induced ROS accumulation in the cytosol of extensor motor cell protoplasts was observed, there was no observable ROS accumulation in the cytosol of flexor motor cell protoplasts, prepared from the abaxial side of the pulvinus (Fig. 3A, 3B and 3C, 3E). Significant cell shrinkage was observed when extensor motor cell protoplasts but not flexor motor cell protoplasts were treated with JAG (Fig. 3D and 3F), consistent with a 
previous result ${ }^{26}$. The time-dependent change of JAG triggered cytosolic ROS accumulation was consistent with that of JAG triggered shrinkage of extensor motor cell protoplasts (Figs. 3C and 3D). The extensor motor cell protoplasts started to shrink within several minutes and reached a plateau within 15 min when treated with JAG, and the JAG-triggered cytosolic ROS accumulation followed the same timecourse. In contrast, JAG treatment had no effect on either ROS accumulation or cell shrinkage of flexor motor cell protoplasts (Figs. 3E and 3F). These results suggest that JAG-triggered ROS accumulation may be involved in JAG induced extensor motor cell shrinkage.

To further assess JAG-induced ROS accumulation, a series of solutions of varying $\mathrm{H}_{2} \mathrm{O}_{2}$ concentration were applied to the protoplasts, instead of JAG. Within 20 min, both $100 \mu \mathrm{M}$ and $1000 \mu \mathrm{M} \mathrm{H}_{2} \mathrm{O}_{2}$ significantly increased ROS accumulation in the cytosol of extensor motor cell protoplasts by up to $40 \%$ and $400 \%$, respectively, whereas no increase in ROS accumulation in protoplasts treated with $10 \mu \mathrm{M} \mathrm{H}_{2} \mathrm{O}_{2}$ was observed (Figure S2). The effect of $100 \mathrm{MM} \mathrm{H}_{2} \mathrm{O}_{2}$ on ROS accumulation in the cytosol of extensor motor cell protoplasts was similar to that of JAG (Figs. $3 \mathrm{C}$ and S2). Therefore, $100 \mu \mathrm{M} \mathrm{H}_{2} \mathrm{O}_{2}$ was used in the subsequent cell volume change experiments. The effect of JAG on the cytosolic ROS accumulation of extensor motor cell protoplasts could be replicated by $100 \mu \mathrm{M} \mathrm{H}_{2} \mathrm{O}_{2}$, which could also induce the shrinkage of extensor motor cell protoplasts (Figure S3). This result suggests that JAG induces extensor motor cell shrinkage through ROS accumulation.

To further assess the role of JAG-induced ROS accumulation in JAG-induced cell shrinkage, the effects of exogenous diphenylene iodonium chloride (DPI), a widely used inhibitor of ROS production by flavoproteins including $\mathrm{RbOH}^{34,41,42}$, and catalase, an $\mathrm{H}_{2} \mathrm{O}_{2}$ scavenger ${ }^{43-45}$, were investigated. Cytosolic ROS accumulation and JAG-induced cell shrinkage were both restricted, even after JAG treatment, in the presence of $12.5 \mu \mathrm{M} \mathrm{DPI}$ (Fig. 4); and the exogenous application of 100 units $\mathrm{mL}^{-1}$ catalase prior to JAG treatment strongly repressed cytosolic ROS accumulation and eliminated JAG-induced cell shrinkage (Figure S4). These results emphasize the importance of ROS accumulation in JAG-triggered extensor motor cell shrinkage.

\section{Expression of outward-rectifying $\mathrm{K}^{+}$channels is indispensable for JAG-induced shrinkage of extensor motor cell protoplasts}

The involvement of $\mathrm{K}^{+}$efflux systems in the JAG-induced shrinkage of Samanea extensor motor cell protoplasts was previously reported ${ }^{16,17}$. Recently, we revealed that SPORK2, a gene encoding the outward-rectifying $\mathrm{K}^{+}$channel of $S$. saman, was responsible for leaf-opening movement ${ }^{28}$. Accordingly, we further examined the role of SPORK2 in JAG-triggered cell shrinkage. Unfortunately, we could not observe direct activation of SPORK2 by the addition of JAG (data not shown). However, we did observe the ion transport activity of SPORK2 in whole-cell patch clamp experiment using isolated Samanea motor cells, as previously reported ${ }^{28}$. In these experiments, signal transduction from NADPH oxidase to SPORK2 did not occur because the cytosolic contents of Samanea motor cells were replaced by the 
pipette solution. On the other hand, when treated with $\mathrm{H}_{2} \mathrm{O}_{2}$, SPORK2 expressed in Xenopus oocyte was activated (Figure S5).

Next, we examined the effect of JAG on extensor motor cells when the expression of SPORK2 was the lowest. To obtain extensor motor cells with the lowest expression level of SPORK2, we checked the expression of SPORK2 in a quarter period of diurnal rhythm containing leaf-folding movement (Figs. 1). SPORK2 expression was highest at Zeitgeber time (ZT) 8 and decreased as the leaves gradually folded, whereas expression of SPORK2 was not fluctuant in flexor during this quarter. In the extensors, expression of SPORK2 reached a nadir at ZT 14. In addition, immunostaining using anti-SPORK2 antibody demonstrated that SPORK2 in tertiary pulvinus decreased as SPORK2 gene expression decreased (Figure S6). We also examined the effect of JAG on the extensor motor cell protoplasts after ZT 14. Interestingly, ROS accumulation was significantly observed in extensor motor cell protoplasts under JAG treatment, whereas no cell shrinkage was observed. Thus, JAG cannot cause shrinkage of extensor motor cell protoplasts with the lowest expression level of SPORK2 gene. On the other hand, in flexor motor cells, there was no specific ZT that caused JAG-induced ROS accumulation as well as cell shrinkage (Figure S7).

\section{Discussion}

Samanea saman is a standard plant in legume nyctinastic leaf movement studies. Recently, JAG was identified as the bioactive metabolite that mediates this leaf-folding movement in $S$. saman ${ }^{25,46}$. JAG is perceived by the extensor motor cells in the Samanea plant body ${ }^{47}$, and selectively induces extensor motor cell shrinkage to cause leaf closure ${ }^{26}$. This is the first report on the molecular mechanism of JAG as a bioactive metabolite in plant which is believed to be a deactivated/storage derivative of $\mathrm{JA}^{39,48}$.

This study examined the involvement of ROS accumulation in the JAG-induced motor cell shrinkage of $S$. saman. The fluorescent dye $\mathrm{H}_{2}$ DCF-DA was used to detect ROS accumulation. ABA and MeJA triggered ROS production in the guard cells of $A$. thaliana as reported previously ${ }^{34-36}$, whereas we found that JAG triggered ROS accumulation in motor cell protoplasts of $S$. saman. This result demonstrated that JAGinduced ROS- accumulation is independent of ABA/JA signaling. The distribution of the accumulation ROS was visualized by confocal laser scanning microscopy (CLSM). JAG-triggered ROS accumulation and JAG-induced cell shrinkage were simultaneously examined in the extensor/flexor motor cells of the Samanea pulvinus. The effect of exogenous DPI chloride (a widely used inhibitor of Rbohs) ${ }^{34}$, catalase (a ROS scavenger $)^{43,49}$ and $\mathrm{H}_{2} \mathrm{O}_{2}$ were all examined. Finally, the mRNA expression of the main outwardrectifying $\mathrm{K}^{+}$channel (SPORK2) was detected, as well as its effect on JAG-triggered ROS accumulation and JAG-induced cell shrinkage. These results strongly suggest that JAG induces motor cell shrinkage through ROS accumulation, and that gene expression of the outwardly-rectifying $\mathrm{K}^{+}$channel is indispensable in JAG-induced cell shrinkage. In addition, JAG induces shrinkage of Samanea motor cells independent of $A B A / J A$ signaling. 
Evidence suggests that the regulation of turgor changes in motor cells is similar to the regulation of turgor changes in stomatal guard cells ${ }^{50}$. ABA triggers $\mathrm{H}_{2} \mathrm{O}_{2}$ accumulation in guard cells of Arabidopsis thaliana through activation of the respiratory burst oxidases multigene family (Rbohs; NADPH oxidases) located on the plasma membrane ${ }^{51,52}$. ABA-regulated stomatal closure is impaired in mutant $A$. thaliana $R b o h D / F(A t r b o h D / F)^{53}$. All of these studies indicated that ROS functions as a second messenger in ABA-induced guard cell shrinkage ${ }^{35,36,42,53}$. ROS as the second messenger have been shown to be involved in various intra- and intercellular signaling event. Jasmonic acid signaling is believed to be involved in stomatal closure ${ }^{38}$. The JA signaling elicitor MeJA triggered ROS accumulation in guard cells of $A$. thaliana (Figs. 2A and C) ${ }^{35,36}$. MeJA-activated ROS production was previously shown to be mediated by the COI1-JAZ signaling module ${ }^{38}$. Here, JAG did not trigger ROS accumulation in guard cells (Figs. 2B and D). These results are consistent with the non-participation of JAG in JA signaling ${ }^{39}$. In contrast, JAG treatment triggered ROS accumulation in extensor motor cell protoplasts, whereas MeJA treatment had no effect on ROS accumulation (Figs. 2B and D). These results suggested that JAGtriggered ROS accumulation is independent of COI1-JAZ signaling module, consistent with a previous report ${ }^{26}$. DPI chloride (Fig. 4) or catalase (Figure S3) repressed JAG-induced ROS accumulation and resulting cell shrinkage in extensor motor cell protoplasts. Considering that catalase would be effective on extracellular ROS, the results suggest that the extracellular $\mathrm{O}^{2-}$ produced by NADPH oxidases dismutate to $\mathrm{H}_{2} \mathrm{O}_{2}$, then it would be transported into the cytosol possibly via aquaporins.

Recently, SPORK2 was shown to be a voltage-dependent outward $\mathrm{K}^{+}$channel that regulates leafmovement. We found that the effect of JAG on extensor cells required SPORK2 and was time-dependent, and that JAG could not shrink protoplasts prepared from folded leaves between ZT 14-18 when the expression of SPORK2 gene was at a minimum (Fig. 5), but that it did induce ROS accumulation within the same time range (Fig. $5 \mathrm{C}$ ). These results suggest that the processes of ROS accumulation and cell shrinkage are linked (by unknown mechanisms) when the leaves are open, but not when they are folded. Given that JAG-induced motor cell shrinkage was impeded by the co-addition of TEA (a blocker of $\mathrm{K}^{+}$ channels) ${ }^{26}$ our current result suggested that SPORK2 is indispensable for JAG-triggered cell shrinkage. It has been reported that ROS accumulation and the subsequent calcium release activate outwardrectifying plant potassium channels, the GUARD CELL OUTWARD-RECTIFYING $\mathrm{K}^{+}$, by a calciumdependent kinase through phosphorylation ${ }^{54}$. Although we did not undertake calcium imaging experiments in $S$. saman (data not shown), a similar phenomenon is presumed to be triggered by JAG in S. saman. it is also possible that ROS directly affects SPORK2, expressed according to circadian rhythms, to regulate its $\mathrm{K}^{+}$transport activity in extensor cells because we confirmed that SPORK2 expressed in Xenopus oocyte was directly activated by ROS (Figure S4). It was reported that post-translational modification of plant $\mathrm{K}^{+}$channels by ROS plays a role in the regulation of $\mathrm{K}^{+}$transport. A heterologously expressed Arabidopsis $\mathrm{K}^{+}$channel, STELAR $\mathrm{K}^{+}$OUTWARD RECTIFIER, directly induces voltage-dependent activation by ROS ${ }^{55}$. In the transmembrane 3 within the voltage sensing complex of STELAR $\mathrm{K}^{+}$ OUTWARD RECTIFIER, Cys-168 was responsible for its activation by ROS. Cys-168 is also present in the 
transmembrane 3 of SPORK2, suggesting a similar activation mechanism for SPORK2 in extensor cells. Further studies will reveal the mechanism of JAG-mediated activation of SPORK2.

Based on the current finding that ROS is involved in JAG-mediated leaf-folding, the JAG-triggered shrinking of the extensor motor cell and outward-rectifying $\mathrm{K}^{+}$-channel SPORK2 can be linked. To elucidate the mode of action on JAG-induced cell shrinkage, the upstream components of ROS accumulation in JAG-induced cell shrinkage are needed. The target protein of JAG is the key to unmask these signaling components.

\section{Conclusion}

In conclusion, our data demonstrates that JAG induces shrinkage of extensor motor cell protoplasts through ROS accumulation, independently of ABA/JA signaling. JAG had no effect ROS accumulation in flexor motor cell protoplasts, but JAG-triggered ROS accumulation occurred in the cytosol of extensor motor cell protoplasts to mediate cell shrinkage, which may trigger the folding of Samanea leaves. All of these results lead to the significant and novel finding that ROS is involved in JAG-induced nyctinastic leaf-folding movement.

\section{Experimental Procedures Plant Materials}

Arabidopsis thaliana (Col-0) was grown in a growth chamber (LPH-240SP, Nippon medical \& chemical instrument Co., Ltd., Osaka, Japan) for 4 to 6 weeks at 20 to $22^{\circ} \mathrm{C}$ and $70 \%$ humidity under a 12-hlight/12-h-dark cycle $\left(66 \mu \mathrm{mol} \mathrm{m} \mathrm{m}^{-2} \mathrm{~s}^{-1} \mathrm{PAR}\right)$.

Seeds of Samanea saman were purchased from World Flower Service Co., Ltd. S. saman trees were grown in a growth chamber (LPH-1PH, Nippon medical \& chemical instrument Co., Ltd. Osaka, Japan) under a 16/8-h light/dark regime at an intensity of 160 to $290 \mu \mathrm{mol} \mathrm{m} \mathrm{m}^{-2} \mathrm{~s}^{-1}$ photosynthetically active radiation (PAR), at $25^{\circ} \mathrm{C} \pm 3{ }^{\circ} \mathrm{C}$, and $70 \%$ relative humidity (the details of light and temperature setting for

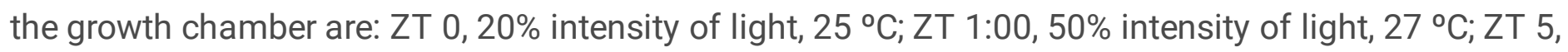
$100 \%$ intensity of light, $27^{\circ} \mathrm{C}$; ZT 11, $50 \%$ intensity of light, $27^{\circ} \mathrm{C}$; ZT $15,20 \%$ intensity of light, $25^{\circ} \mathrm{C}$; ZT 16 , dark, $22^{\circ} \mathrm{C}$ ). The study on this plant species has comply with relevant institutional, national, and international guidelines and legislation.

\section{Preparation of Samanea motor cell protoplasts for ROS detection}

Tertiary pulvini protoplasts were isolated from third to fifth branch from the shoot apex of the Samanea trees during ZT $3-5$ according to the previously reported method $26,56,57$, with modifications. About 100 of the tertiary pulvini were separated into extensor (adaxial) part and flexor (abaxial) part with a sharp razor blade and placed in $1 \mathrm{~mL}$ of predigestion solution (Gamborg's B-5, $0.3 \mathrm{M}$ sorbitol, $50 \mathrm{mM}$ MES-KOH (pH 
5.5), $0.2 \% \mathrm{BSA}, 8 \mathrm{mM} \mathrm{CaCl}_{2}$ ). The osmotic pressure of the predigestion solution was then raised to $0.6 \mathrm{M}$ sorbitol in two steps over 20 min with osmotic adjustment solution (Gamborg's B-5, 4.0 M sorbitol, 50 mM MES-KOH (pH 5.5), $0.2 \% \mathrm{BSA}, 8 \mathrm{mM} \mathrm{CaCl}_{2}$ ). Tissues were then moved into a $\phi 35 \mathrm{~mm}$ tissue culture dish with $1.6 \mathrm{~mL}$ filtered enzyme solution (Gamborg's B-5, $50 \mathrm{mM}$ MES-KOH (pH 5.5), $0.4 \mathrm{M}$ sorbitol, $0.2 \% \mathrm{BSA}$, $8 \mathrm{mM} \mathrm{CaCl} 2,3 \%$ (w/v) each of Driselase (Aska Pharmaceutical Co. Ltd., Tokyo, Japan), Macerozyme R-10 and cellulase Onozuka RS, 0.3\% pectolyase Y-23 (Yakult Pharmaceutical Industry Co., Ltd., Tokyo, Japan). Tissues in the enzyme solution were incubated with mild shaking for $1 \mathrm{~h}$ at $30^{\circ} \mathrm{C}$, then without shaking for $1 \mathrm{~h}$ at $30^{\circ} \mathrm{C}$. The enzyme solution was discarded and the tissues rinsed with recovering solution ( $3 \times 1 \mathrm{~mL}$, Gamborg's B-5, $0.35 \mathrm{M}$ sorbitol, $20 \mathrm{mM}$ MES-Tris (pH 5.5), $100 \mathrm{mM} \mathrm{KCl}$, and $1 \mathrm{mM}$ $\mathrm{CaCl}_{2}$ ). The protoplasts were released in $1.6 \mathrm{~mL}$ recovering solution for $0.5-1 \mathrm{~h}$ at $30^{\circ} \mathrm{C}$ and debris removed by filtration of the protoplast suspension through a $50 \mu \mathrm{m}$ nylon mesh. This step was repeated twice. The collected protoplasts were incubated at room temperature $\left(24^{\circ} \mathrm{C}\right)$ for $3-4 \mathrm{~h}$. Afterward, the protoplasts were concentrated on a sucrose cushion ( $0.57 \mathrm{M}$ sucrose, $20 \mathrm{mM}$ MES-Tris (pH 5.5), $10 \mathrm{mM}$ $\mathrm{KCl}, 1 \mathrm{mM} \mathrm{CaCl}_{2}$ ) by centrifugation at $60 \times \mathrm{g}$ for $5 \mathrm{~min}$ and subsequently further purified on sucrose gradient: protoplasts were suspended with $0.8 \mathrm{~mL} \sim 80 \%$ sucrose cushion in a $2 \mathrm{~mL}$ Eppendorf tube, then $0.5 \mathrm{~mL}$ mix solution (sucrose cushion : wash solution $=4: 3$, wash solution: $0.57 \mathrm{M}$ sorbitol, $20 \mathrm{mM}$ MESTris ( $\mathrm{pH}$ 5.5), $10 \mathrm{mM} \mathrm{KCl}, 1 \mathrm{mM} \mathrm{CaCl}_{2}$ ) was layered on top of the protoplast suspension and $0.5 \mathrm{~mL}$ wash solution was layered in upper part. The gradient was centrifuged at $130 \times \mathrm{g}$ for $10 \mathrm{~min}$. The purified protoplasts were collected at the interphase between wash solution and mixed solutions. The yield of protoplasts was 1.5 to $3 \times 10^{5}$.

\section{Measurement of ROS for motor cell protoplasts of S. saman using CLSM}

The protoplasts were isolated as described above. Prepared protoplasts $(10,000$ cells $/ \mathrm{mL})$ in $130 \mu \mathrm{L}$ wash solution were sealed in a glass-bottom Petri dish ( $\varphi 35 \mathrm{~mm} \times 12 \mathrm{~mm}$ ) coated with $200 \mu \mathrm{L}$ of $\mathrm{H}_{2} \mathrm{O}$

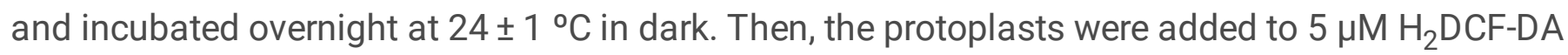
(Sigma-Aldrich Co., Ltd., MO, USA), incubated for $45 \mathrm{~min}$ to stabilize their initial fluorescence intensity, and imaged by CLSM (LSM 700, Carl Zeiss, Oberkochen, Germany) at 2-min intervals for 20 min after treatment with $100 \mu \mathrm{M} \mathrm{JAG}{ }^{26}$ dissolved in $0.1 \%$ DMSO, $\mathrm{H}_{2} \mathrm{O}_{2}$ (FUJIFILM Wako Pure Chemical Industries Co., Osaka, Japan) at the indicated concentration, mock (0.01\% ethanol or DMSO for DPI), or blank (untreated with any chemicals). When used, $12.5 \mu \mathrm{M}$ DPI (Sigma-Aldrich Co., Ltd., MO, USA) dissolved in DMSO or $100 \mathrm{U} / \mathrm{ml}$ catalase (Sigma Co., Ltd.) was added $30 \mathrm{~min}$ before treatment with the above compounds. Intercellular fluorescence was excited using $488 \mathrm{~nm}$ light emitted by a solid-state diode laser at $0.5 \%$ with a Plan-Apochromat $40 \times / 1.3$ oil immersion objective and other settings as follows: emission 495-628 nm, master gain 500-650, pinhole $0.9 \mu \mathrm{m}$, 8-bit, frame $1024 \times 1024$ pixel, zoom 1.0, pixel dwell time $1.58 \mu \mathrm{sec} / \mathrm{pixel}$ and line average of 4 . Autofluorescence was negligible in this emission range using these settings. Zen 2012 Black Edition software (Carl Zeiss, Oberkochen, Germany) was used for image analysis. Photobleaching and dye leakage from the intercellular to adjacent areas was too low to detect under these conditions. Dye leakage from the cytosol to the vacuole was assessed by comparing the levels of vacuole fluorescence at the end and beginning of each experiment. The round protoplasts were 
selected in which vacuole fluorescence intensity was less than twice as strong as that of background solution. However, the protoplast was discarded if dye leakage from the cytosol to the vacuole had increased the intensity of vacuole fluorescence up to $200 \%$. ROS accumulation was calculated based on the fluorescence intensity of $\mathrm{H}_{2}$ DCF-DA. The ROS accumulation of $\mathrm{H}_{2}$ DCF-loaded protoplasts induced by blue light and the dark conditions was recorded with none-treatment as blank. ROS accumulation was estimated with the following equation:

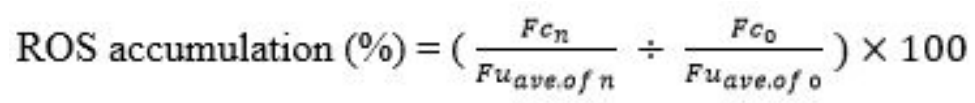

$\left(F c_{n}=\right.$ the fluorescence intensity of a protoplast treated with chemicals at $n^{\text {th }}$ minutes. $n=0,2,4, \ldots 20$.

$\mathrm{Fu}_{\text {ave.of } \mathrm{n}}=$ average of the fluorescence intensity of untreated protoplasts at $\mathrm{n}^{\text {th }}$ minutes. $\mathrm{Fc}_{0}=$ the fluorescence intensity of a protoplast treated with chemicals at 0 minutes. $\mathrm{Fu}_{\text {ave.of } 0}=$ average of the fluorescence intensity of untreated protoplasts at 0 minutes). Pixel intensities of fluorescence at each given time were collected as the average intensity of three points that were away from the chloroplasts and vacuoles in each cell. Data were collected from two experiments in parallel on the same day.

\section{Measurement of cell shrinkage for motor cell protoplasts of S. saman using CLSM}

The protoplasts selected for measuring the cytosol fluorescence intensity were used for measuring the cell shrinkage. First, the intensity of the ROS signal was adjusted into similar-level contrast in the same protoplasts at the denoted times. Then, a red circle was made to fit the edge (critical surface of ROS signal) of the round part of the protoplast. The area of the red circle was calculated based on the average area of two independent fitting processes, and the changes in normalized protoplast volume calculated.

\section{Quantitative RT-PCR analysis of SPORK2}

To analyze time-course gene expression profiles of SPORK2 in Samanea tertiary pulvini, excised extensor and flexor motor cells were sampled every 2 hours from ZT 8 to ZT 14. Total RNA was isolated using the RNeasy Plant Mini Kit (QIAGEN, Hilden, Germany), and cDNA was synthesized using ReverTra Ace (TOYOBO, Osaka, Japan) with oligo(dT) 20 primers. Quantitative PCR was performed on a StepOnePlus Real-Time PCR System (Thermo Fisher Scientific, CA, USA) with KAPA SYBR Fast qPCR Kit (KAPA Biosystems, MA, USA). The following primers were used; forward, 5'-TGCTGGTAAAATCACCAATACC-3', reverse, 5'- GCCGTGATAAATTATCACAC-3'.

\section{Declarations}

\section{Acknowledgement}

This work was financially supported by a Grant-in-Aid for Scientific Research for MU from JSPS, Japan (nos. 17H06407, 18KK0162, and 20H00402), JSPS A3 Foresight Program (MU), and JSPS Core-to-Core Program Asian Chemical Biology Initiative (MU). And we would like to express our sincere thanks 
to Dr. Hiroaki Mano and Prof. Mitsuyasu Hasebe (Division of Evolutionary Biology, National Institute for Basic Biology) for their efforts to genetically transform Samanea saman. We also thank to Dr. Yousuke Takaoka (Tohoku University) for technical assistance of calcium imaging.

\section{Data availability}

The datasets generated and/or analysed during the current study are reported in the references cited or available from the corresponding author, Minoru Ueda, upon request.

\section{Supporting information}

This article contains supporting information (Figure S1-S5).

\section{Funding}

This work was financially supported by a Grant-in-Aid for Scientific Research for MU from JSPS, Japan (nos. 17H06407, 18KK0162, and 20H00402), JSPS A3 Foresight Program (MU), and JSPS Core-to-Core Program Asian Chemical Biology Initiative (MU).

\section{Author contributions}

Conceptualization, M.U.; Methodology, M.U., and Y. I.; Investigation, G. Y. and Y. I., N.U.; Writing - Original Draft, G. Y. and M. U.; Writing - Review \& Editing, Y.I.; Visualization, Y.M., and S.H.; Funding Acquisition, M. U.; Resources, M.U., and G. Y.; Supervision, M. U.

\section{Conflicts of interest}

There are no conflicts to declare.

\section{References}

1. Moran, N. in Rhythms in Plants Ch. Chapter 4, 57-95 (2015).

2. Moran, N. Osmoregulation of leaf motor cells. Febs Lett 581, 2337-2347, doi:10.1016/j.febslet.2007.04.002 (2007).

3. Satter, R. L., Gorton, H. L. \& Vogelmann, T. C. The pulvinus: motor organ for leaf movement. (American Society of Plant Physiologists, 1990).

4. Schildknecht, H. Turgorins, Hormones of the Endogeneous Daily Rhythms of Higher Organized Plants -Detection, Isolation, Structure, Synthesis, and Activity. Angewandte Chemie International Edition in English 22, 695-710, doi:10.1002/anie.198306951 (1983).

5. de Mairan, J. Observation botanique. Hist. Acad. Roy. Sci 362, 103-113 (1729).

6. Darwin, C. \& Darwin, F. The power of movement in plants, third thousand. (John Murray, 1882). 
7. Palmer, J. H. \& Asprey, G. F. Studies in the nyctinastic movement of the leaf pinnae of Samanea saman (Jacq.) Merrill. Planta 51, 757-769, doi:10.1007/bf01941002 (1958).

8. Palmer, J. H. \& Asprey, G. F. Studies in the nyctinastic movement of the leaf pinnae of Samanea saman (Jacq.) Merrill. Planta 51, 770-785, doi:10.1007/bf01941003 (1958).

9. Satter, R. L. \& Galston, A. W. Leaf Movements: Rosetta Stone of Plant Behavior? Bioscience 23, 407416, doi:10.2307/1296540 (1973).

10. Satter, R. L., Geballe, G. T., Applewhite, P. B. \& Galston, A. W. Potassium flux and leaf movement in Samanea saman. I. Rhythmic movement. Journal of General Physiology 64, 413-430 (1974).

11. Satter, R. L., Geballe, G. T. \& Galston, A. W. Potassium flux and leaf movement in Samanea saman. II. Phytochrome controlled movement. Journal of General Physiology 64, 431-442 (1974).

12. Simon, E., Satter, R. L. \& Galston, A. W. Circadian rhythmicity in excised samanea pulvini: I. Sucrosewhite light interactions. Plant Physiology 58, 417-420 (1976).

13. Simon, E., Satter, R. L. \& Galston, A. W. Circadian Rhythmicity in Excised Samanea Pulvini: II. Resetting the Clock by Phytochrome Conversion. Plant Physiology 58, 421-425 (1976).

14. Gorton, H. L. \& Satter, R. L. Extensor and Flexor Protoplasts from Samanea Pulvini: II. X-Ray Analysis of Potassium, Chlorine, Sulfur, Phosphorus, and Calcium. Plant Physiology 76, 685-690 (1984).

15. Gorton, H. L. \& Satter, R. L. Extensor and flexor protoplasts from samanea pulvini: I. Isolation and initial characterization. Plant Physiology 76, 680-684 (1984).

16. Moshelion, M. et al. Diurnal and circadian regulation of putative potassium channels in a leaf moving organ. Plant Physiology 128, 634-642, doi:10.1104/pp.010549 (2002).

17. Moshelion, M. \& Moran, N. Potassium-efflux channels in extensor and flexor cells of the motor organ of Samanea saman are not identical. Effects of cytosolic calcium. Plant Physiol 124, 911-919 (2000).

18. Yu, L. et al. Phosphorylation of SPICK2, an AKT2 channel homologue from Samanea motor cells. Journal of Experimental Botany 57, 3583-3594, doi:10.1093/jxb/erl104 (2006).

19. Yu, L., Moshelion, M. \& Moran, N. Extracellular protons inhibit the activity of inward-rectifying potassium channels in the motor cells of Samanea saman pulvini. Plant Physiology 127, 13101322 (2001).

20. Moshelion, M. et al. Plasma membrane aquaporins in the motor cells of Samanea saman: diurnal and circadian regulation. Plant Cell 14, 727-739, doi:Doi 10.1105/Tpc.010351 (2002).

21. Satter, R. L., Guggino, S. E., Lonergan, T. A. \& Galston, A. W. The effects of blue and far red light on rhythmic leaflet movements in samanea and albizzia. Plant Physiology 67, 965-968 (1981).

22. Suh, S., Moran, N. \& Lee, Y. Blue light activates potassium-efflux channels in flexor cells from Samanea saman motor organs via two mechanisms. Plant Physiology 123, 833-843 (2000).

23. Ueda, M. \& Yamamura, S. Chemistry and biology of plant leaf movements. Angewandte Chemie International Edition 39, 1400-1414, doi:10.1002/(sici)1521-3773(20000417)39:8<1400::aidanie1400>3.0.co;2-z (2000). 
24. Ueda, M. \& Nakamura, Y. Chemical basis of plant leaf movement. Plant and Cell Physiology 48, $900-$ 907, doi:10.1093/pcp/pcm060 (2007).

25. Ueda, M. \& Nakamura, Y. Metabolites involved in plant movement and 'memory': nyctinasty of legumes and trap movement in the Venus flytrap. Nat Prod Rep 23, 548-557, doi:10.1039/b515708k (2006).

26. Nakamura, Y. et al. 12-hydroxyjasmonic acid glucoside is a COI1-JAZ-independent activator of leafclosing movement in Samanea saman. Plant Physiol 155, 1226-1236, doi:10.1104/pp.110.168617 (2011).

27. Nakamura, Y., Miyatake, R. \& Ueda, M. Enantiodifferential approach for the detection of the target membrane protein of the jasmonate glycoside that controls the leaf movement of Albizzia saman. Angewandte Chemie. International Ed. In English 47, 7289-7292, doi:10.1002/anie.200801820 (2008).

28. Oikawa, T. et al. Ion Channels Regulate Nyctinastic Leaf Opening in < em > Samanea saman</em>. Current Biology 28, 2230-2238.e2237, doi:10.1016/j.cub.2018.05.042 (2018).

29. Ueda, M., Ishimaru, Y., Takeuchi, Y. \& Muraoka, Y. Plant nyctinasty - who will decode the 'Rosetta Stone'? New Phytol 0, doi:10.1111/nph.15717 (2019).

30. Munemasa, S. et al. Mechanisms of abscisic acid-mediated control of stomatal aperture. Curr Opin Plant Biol 28, 154-162, doi:10.1016/j.pbi.2015.10.010 (2015).

31. Assmann, S. M. \& Jegla, T. Guard cell sensory systems: recent insights on stomatal responses to light, abscisic acid, and CO2. Current Opinion in Plant Biology 33, 157-167, doi:http://dx.doi.org/10.1016/j.pbi.2016.07.003 (2016).

32. Kim, T. H., Bohmer, M., Hu, H., Nishimura, N. \& Schroeder, J. I. Guard cell signal transduction network: advances in understanding abscisic acid, $\mathrm{CO} 2$, and $\mathrm{Ca} 2+$ signaling. Annual Review of Plant Biology 61, 561-591, doi:10.1146/annurev-arplant-042809-112226 (2010).

33. Song, Y., Miao, Y. \& Song, C.-P. Behind the scenes: the roles of reactive oxygen species in guard cells. New Phytologist 201, 1121-1140, doi:https://doi.org/10.1111/nph.12565 (2014).

34. Suhita, D., Raghavendra, A. S., Kwak, J. M. \& Vavasseur, A. Cytoplasmic alkalization precedes reactive oxygen species production during methyl jasmonate- and abscisic acid-induced stomatal closure. Plant Physiol. 134, 1536-1545, doi:10.1104/pp.103.032250 (2004).

35. Murata, Y., Pei, Z., Mori, I. \& Schroeder, J. Abscisic acid activation of plasma membrane $\mathrm{Ca}(2+)$ channels in guard cells requires cytosolic $\mathrm{NAD}(\mathrm{P}) \mathrm{H}$ and is differentially disrupted upstream and downstream of reactive oxygen species production in abi1-1 and abi2-1 protein phosphatase 2C mutants. Plant Cell 13, 2513-2523, doi:10.1105/tpc.010210 (2001).

36. Ye, W. et al. Endogenous abscisic acid is involved in methyl jasmonate-induced reactive oxygen species and nitric oxide production but not in cytosolic alkalization in Arabidopsis guard cells. J. Plant Physiol. 170, 1212-1215, doi:10.1016/j.jplph.2013.03.011 (2013).

37. Fonseca, S., Chico, J. M. \& Solano, R. The jasmonate pathway: the ligand, the receptor and the core signalling module. Curr. Opin. Plant Biol. 12, 539-547, doi:10.1016/j.pbi.2009.07.013 (2009). 
38. Munemasa, S. et al. The coronatine-insensitive 1 mutation reveals the hormonal signaling interaction between abscisic acid and methyl jasmonate in Arabidopsis guard cells. Specific impairment of ion channel activation and second messenger production. Plant Physiol. 143, 1398-1407, doi:10.1104/pp.106.091298 (2007).

39. Miersch, O., Neumerkel, J., Dippe, M., Stenzel, I. \& Wasternack, C. Hydroxylated jasmonates are commonly occurring metabolites of jasmonic acid and contribute to a partial switch-off in jasmonate signaling. New Phytologist 177, 114-127, doi:10.1111/j.1469-8137.2007.02252.x (2008).

40. Wrzaczek, M., Brosche, M. \& Kangasjarvi, J. ROS signaling loops - production, perception, regulation. Curr. Opin. Plant Biol. 16, 575-582, doi:10.1016/j.pbi.2013.07.002 (2013).

41. Kleniewska, P., Piechota, A., Skibska, B. \& Goraca, A. The NADPH oxidase family and its inhibitors. Arch. Immunol. Ther. Exp. (Warsz.) 60, 277-294, doi:10.1007/s00005-012-0176-z (2012).

42. Pei, Z. M. et al. Calcium channels activated by hydrogen peroxide mediate abscisic acid signalling in guard cells. Nature 406, 731-734, doi:10.1038/35021067 (2000).

43. Zhang, X. et al. Hydrogen peroxide is involved in abscisic acid-induced stomatal closure in Vicia faba. Plant Physiol. 126, 1438-1448, doi:DOI 10.1104/pp.126.4.1438 (2001).

44. Alvarez, M. E. et al. Reactive oxygen intermediates mediate a systemic signal network in the establishment of plant immunity. Cell 92, 773-784, doi:10.1016/s0092-8674(00)81405-1 (1998).

45. Levine, A., Tenhaken, R., Dixon, R. \& Lamb, C. H2O2 from the oxidative burst orchestrates the plant hypersensitive disease resistance response. Cell 79, 583-593, doi:10.1016/0092-8674(94)90544-4 (1994).

46. Ueda, M., Okazaki, M., Ueda, K. \& Yamamura, S. A Leaf-Closing Substance of Albizzia julibrissin Durazz. Tetrahedron 56, 8101-8105, doi:10.1016/s0040-4020(00)00729-8 (2000).

47. Nakamura, Y., Miyatake, R. \& Ueda, M. Enantiodifferential Approach for the Detection of the Target Membrane Protein of the Jasmonate Glycoside that Controls the Leaf Movement of Albizzia saman. Angewandte Chemie International Edition 47, 7289-7292, doi:doi:10.1002/anie.200801820 (2008).

48. Haroth, S. et al. The glycosyltransferase UGT76E1 significantly contributes to 12-0-glucopyranosyljasmonic acid formation in wounded Arabidopsis thaliana leaves. Journal of Biological Chemistry 294, 9858-9872, doi:10.1074/jbc.RA119.007600 (2019).

49. Allan, A. C. \& Fluhr, R. Two Distinct Sources of Elicited Reactive Oxygen Species in Tobacco Epidermal Cells. Plant Cell 9, 1559-1572, doi:10.1105/tpc.9.9.1559 (1997).

50. Cote, G. G. Signal Transduction in Leaf Movement. Plant Physiol. 109, 729-734 (1995).

51. Yoshida, R. et al. ABA-activated SnRK2 protein kinase is required for dehydration stress signaling in Arabidopsis. Plant Cell Physiol. 43, 1473-1483, doi:10.1093/pcp/pcf188 (2002).

52. Mustilli, A. C., Merlot, S., Vavasseur, A., Fenzi, F. \& Giraudat, J. Arabidopsis OST1 protein kinase mediates the regulation of stomatal aperture by abscisic acid and acts upstream of reactive oxygen species production. Plant Cell 14, 3089-3099, doi:10.1105/tpc.007906 (2002). 
53. Kwak, J. M. et al. NADPH oxidase AtrbohD and AtrbohF genes function in ROS-dependent ABA signaling in Arabidopsis. EMBO J. 22, 2623-2633, doi:10.1093/emboj/cdg277 (2003).

54. Förster, S. et al. Wounding-Induced Stomatal Closure Requires Jasmonate-Mediated Activation of GORK K + Channels by a Ca2 + Sensor-Kinase CBL1-CIPK5 Complex. Developmental cell, doi:https://doi.org/10.1016/j.devcel.2018.11.014 (2018).

55. Garcia-Mata, C. et al. A minimal cysteine motif required to activate the SKOR K + channel of Arabidopsis by the reactive oxygen species H2O2. Journal of Biological Chemistry 285, 2928629294, doi:10.1074/jbc.M110.141176 (2010).

56. Gorton, H. L. \& Satter, R. L. Extensor and flexor protoplasts from samanea pulvini: I. Isolation and initial characterization. Plant Physiol. 76, 680-684 (1984).

57. Moran, N., Fox, D. \& Satter, R. L. Interaction of the Depolarization-Activated K Channel of Samanea saman with Inorganic lons: A Patch-Clamp Study. Plant Physiol. 94, 424-431 (1990).

58. Kato, Y. et al. Evidence in support of a four transmembrane-pore-transmembrane topology model for the Arabidopsis thaliana $\mathrm{Na}+/ \mathrm{K}+$ translocating AtHKT1 protein, a member of the superfamily of $\mathrm{K}+$ transporters. Proceedings of the National Academy of Sciences 98, 6488-6493, doi:10.1073/pnas.101556598 (2001).

\section{Figures}


A

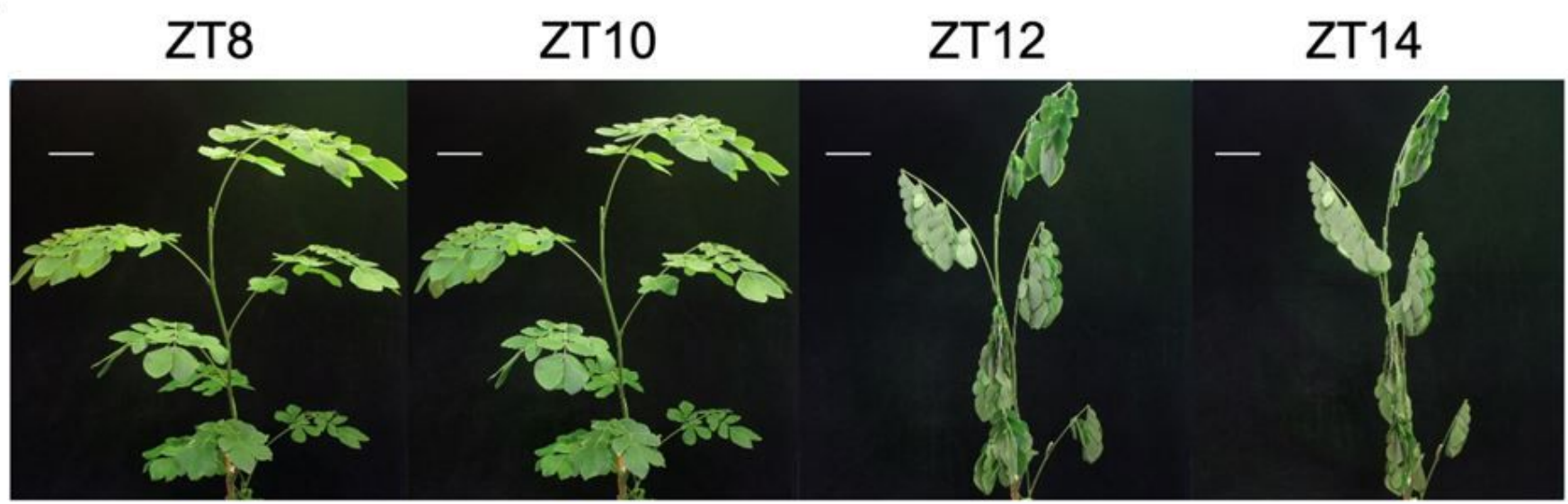

B

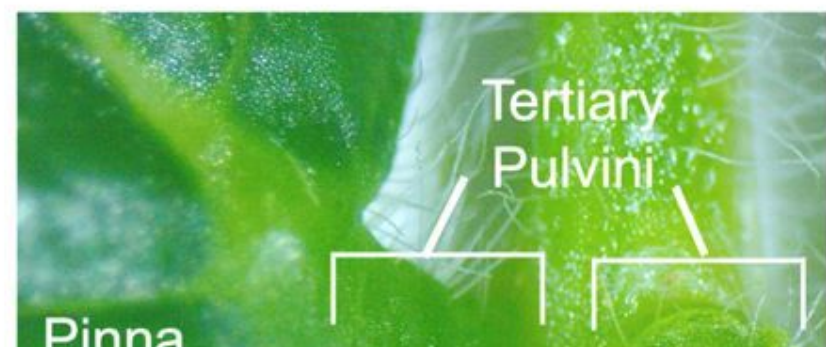

C

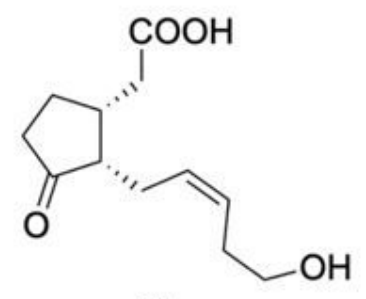

JA

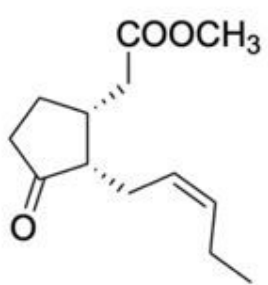

MeJA

\section{Extensor Flexor}

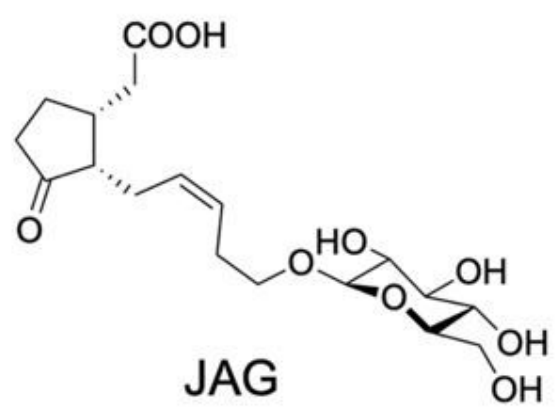

Figure 1

Samanea saman is a standard plant in the study of nyctinasty

(A) The images of $S$. saman during a quarter of circadian rhythm from ZT 8 -14 containing leaf-folding movement. $B a r=10 \mathrm{~cm}$.

(B) Enlarged image of tertiary pulvini of $S$. saman. Note that adaxial side is extensor and abaxial side is flexor. Bar $=1 \mathrm{~mm}$.

(C) Chemical structures of jasmonates. jasmonic acid (JA), methyl jasmonate (MeJA), 12 -

hydroxyjasmonic acid glucoside (JAG). Note that JAG is the endogenous chemical factor which induces leaf-folding of $S$. saman. 
A

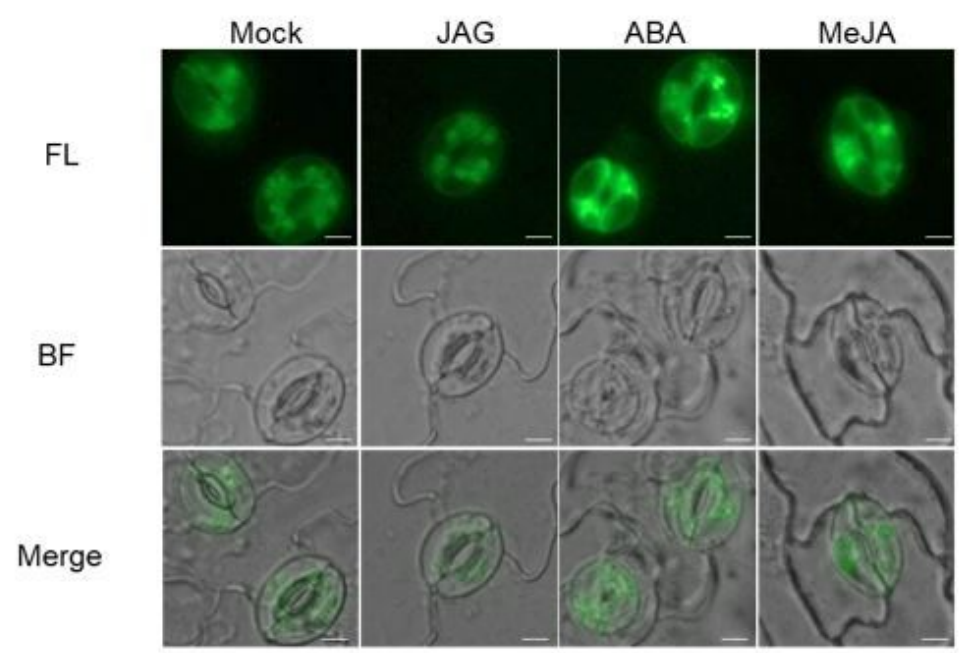

B

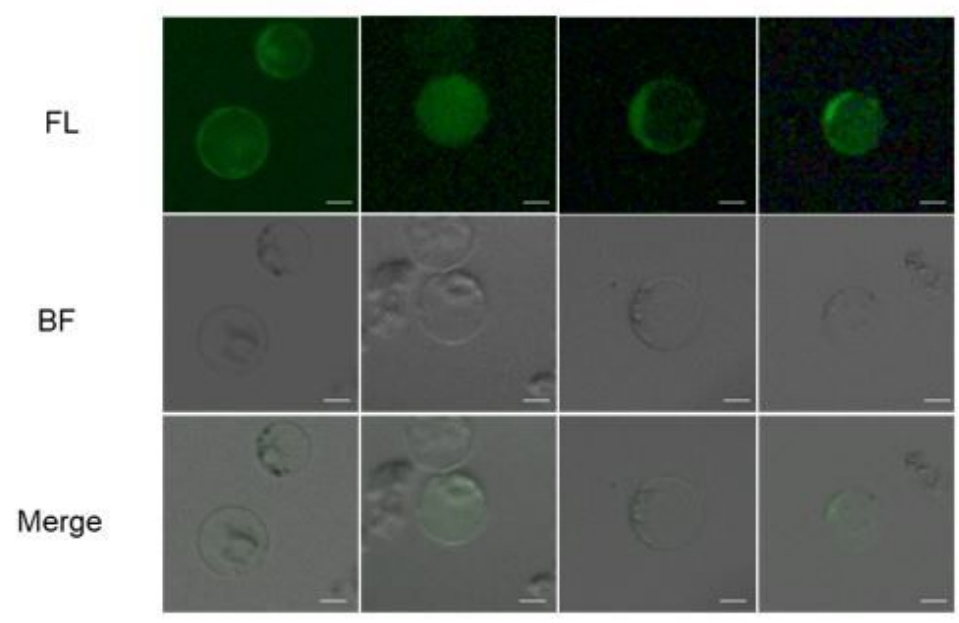

C

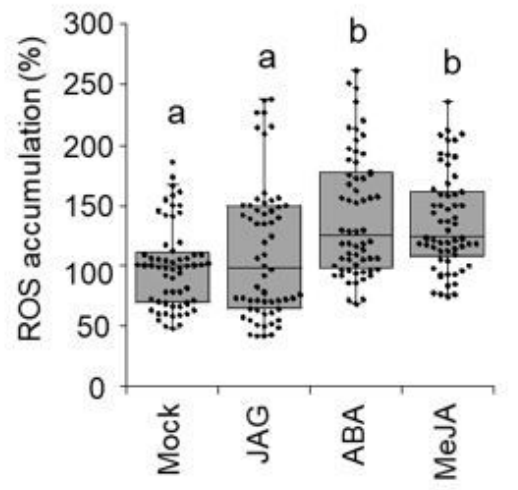

D

\section{Figure 2}

JAG induced ROS accumulation in tertiary extensor motor cell protoplasts of $S$. saman.

(A) and (B) Representative images of ROS accumulation visualized by fluorescent dye DCF. Epidermal peels of $A$. thaliana (A) were loaded with $\mathrm{H}_{2}$ DCFDA for 30 min before adding $100 \mu \mathrm{M} \mathrm{JAG}, 10 \mu \mathrm{M}$ ABA or $10 \mu \mathrm{M}$ MeJA or tertiary extensor motor cell protoplasts of $S$. saman $(B)$ were loaded with $\mathrm{H}_{2}$ DCFDA for 30 
min before adding $100 \mu \mathrm{M}$ JAG, $100 \mu \mathrm{M}$ ABA or $100 \mu \mathrm{M}$ MeJA. Photomicrographs were taken 20 min or 15 min after treatment (epidermal peels of $A$. thaliana) or after 15 min after treatment (tertiary extensor motor cell protoplasts of $S$. saman). The experiments of S.saman protoplasts were performed during ZT 6-11. Bar $=10 \mu \mathrm{m}$.

(C) Quantification of ROS accumulation in guard cells of $A$. thaliana following above treatment as in (A). Box plots represents fluorescence intensity ratio of treated cells to mock cells. All data are represented as dot plots $(n=60)$. Mean \pm SE are as follows: Mock; $100.0 \pm 4.5$, JAG; $141.5 \pm 6.5$, ABA; $107.4 \pm 3.9$, MeJA; $111.9 \pm 7.3$.

(D) Quantification of ROS accumulation in tertiary extensor motor cell protoplasts of $S$. saman following above treatment as in (B). Box plots represents fluorescence intensity ratio of treated cells to mock cells All data are represented as dot plots $(n=61-92)$. Mean \pm SE are as follows: Mock; $100.0 \pm 6.4$, JAG; 131.5 $\pm 5.9, \mathrm{ABA} ; 106.3 \pm 6.7, \mathrm{MeJA} ; 108.4 \pm 5.6$. Different letters indicate significant differences (SNK post-hoc test, $\mathrm{P}<0.05)$ in $(\mathbf{C})$ and $(\mathbf{D})$. 
A

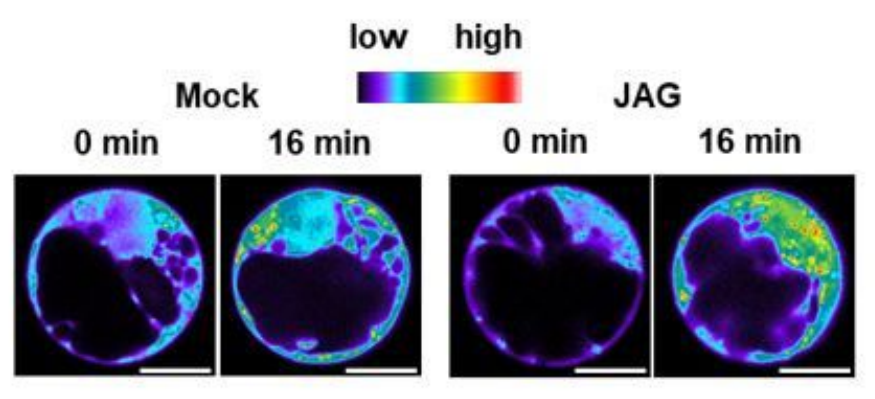

C

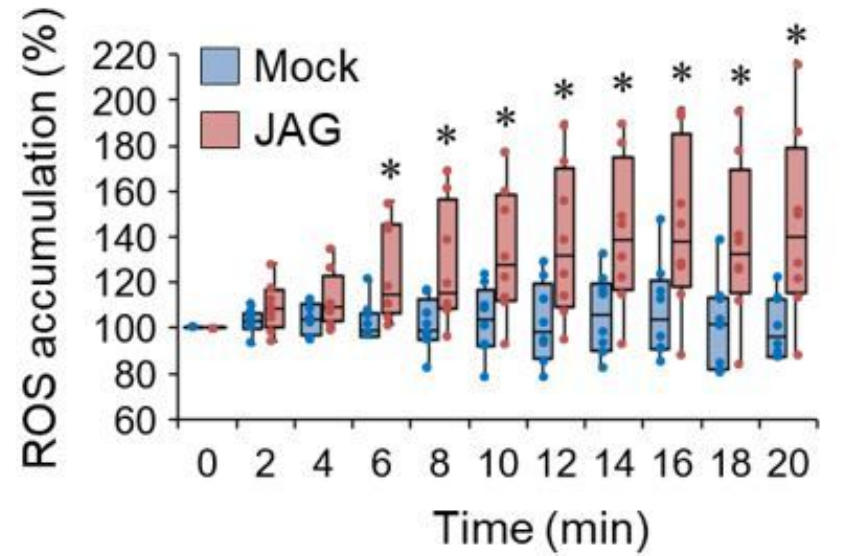

E

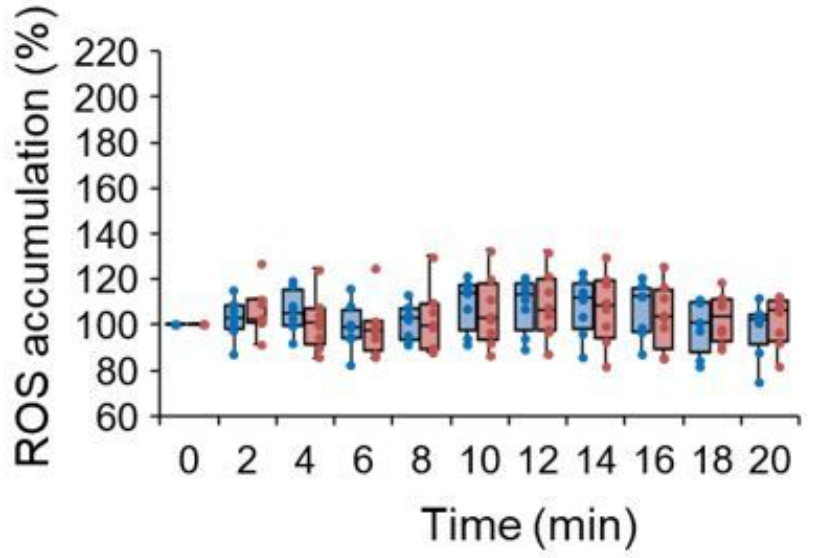

B

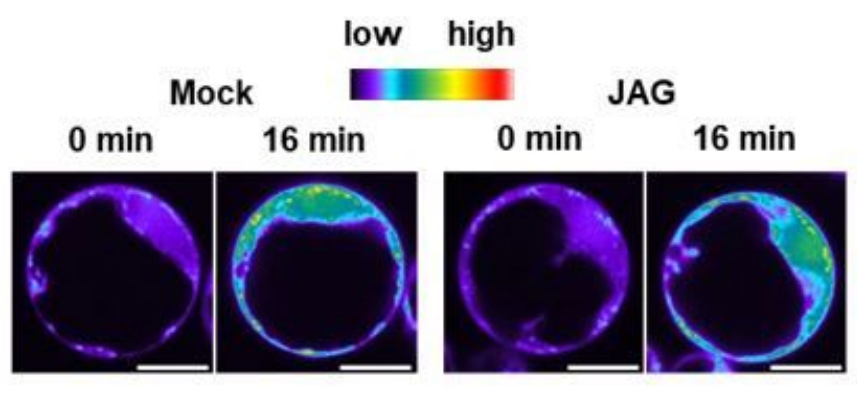

D

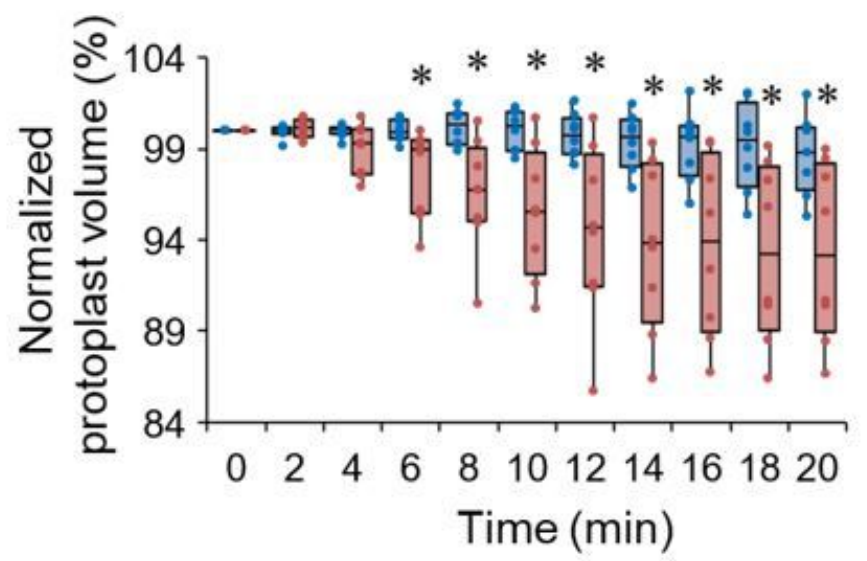

$\mathbf{F}$

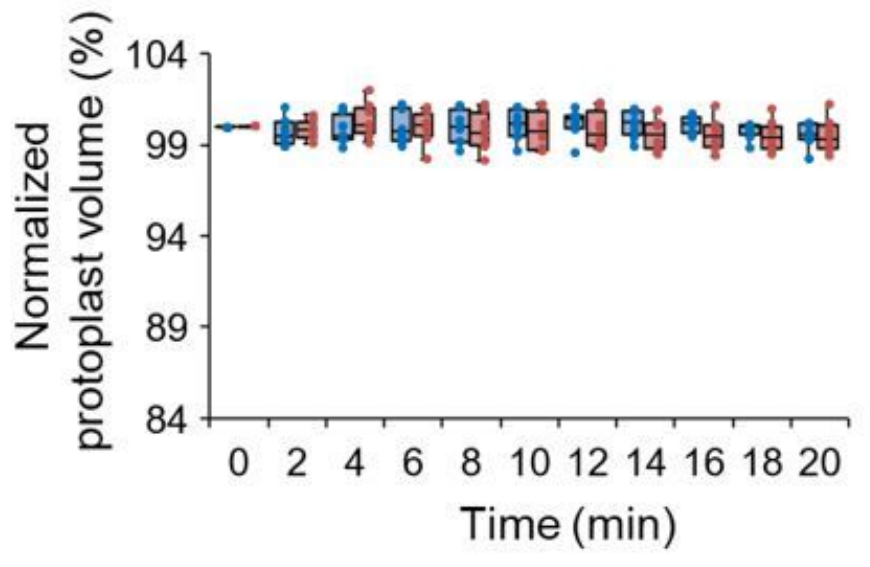

Figure 3

JAG induced ROS accumulation was involved in leaf-close movement of $S$. saman

(A) and (B) Representative images of ROS accumulation in extensor (A) or flexor (B) indicated by fluorescent dye DCF. Motor cell protoplasts of $S$. saman were loaded with $\mathrm{H}_{2}$ DCFDA for 45 min before adding $100 \mu \mathrm{M}$ JAG. Photomicrographs were taken at $0 \mathrm{~min}$ and $16 \mathrm{~min}$ after above treatments by CLSM. Bar $=10 \mu \mathrm{m}$. 
(C) and (D) Box plots represent time course of JAG induced cytosolic ROS accumulation (C) and cell shrinkage (D) in tertiary extensor protoplasts of $S$. saman following above treatment as in (A). All data points are shown as dot plots $(n=8)$.

(E) and (F) Box plots represent time course of JAG induced cytosolic ROS accumulation (E) and cell shrinkage $(\mathbf{F})$ in tertiary flexor protoplasts of $S$. saman following above treatment as in (B). All data points are shown as dot plots $(n=8)$. Asterisks indicate significant differences ( ${ }^{*} p<0.05 ;$ t test) in (C) - (F). All experiments were conducted during ZT 6-11. Four independent experiments were performed.

A

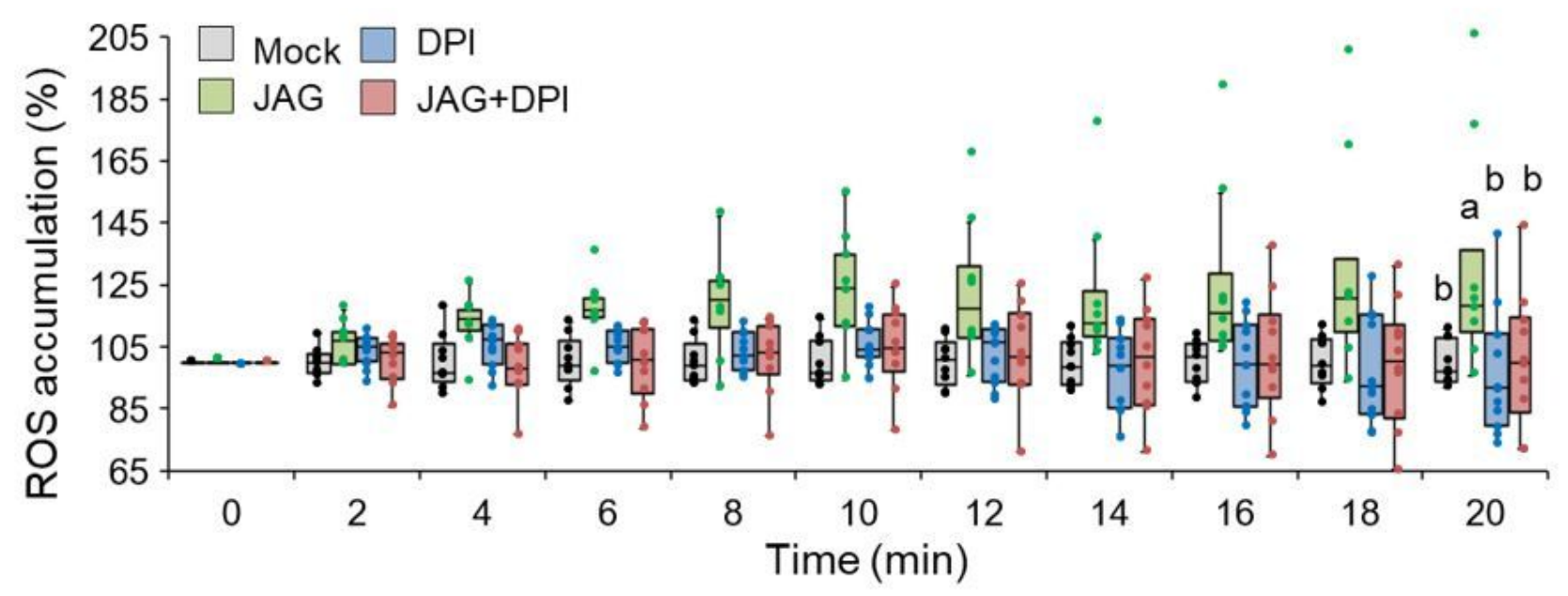

B

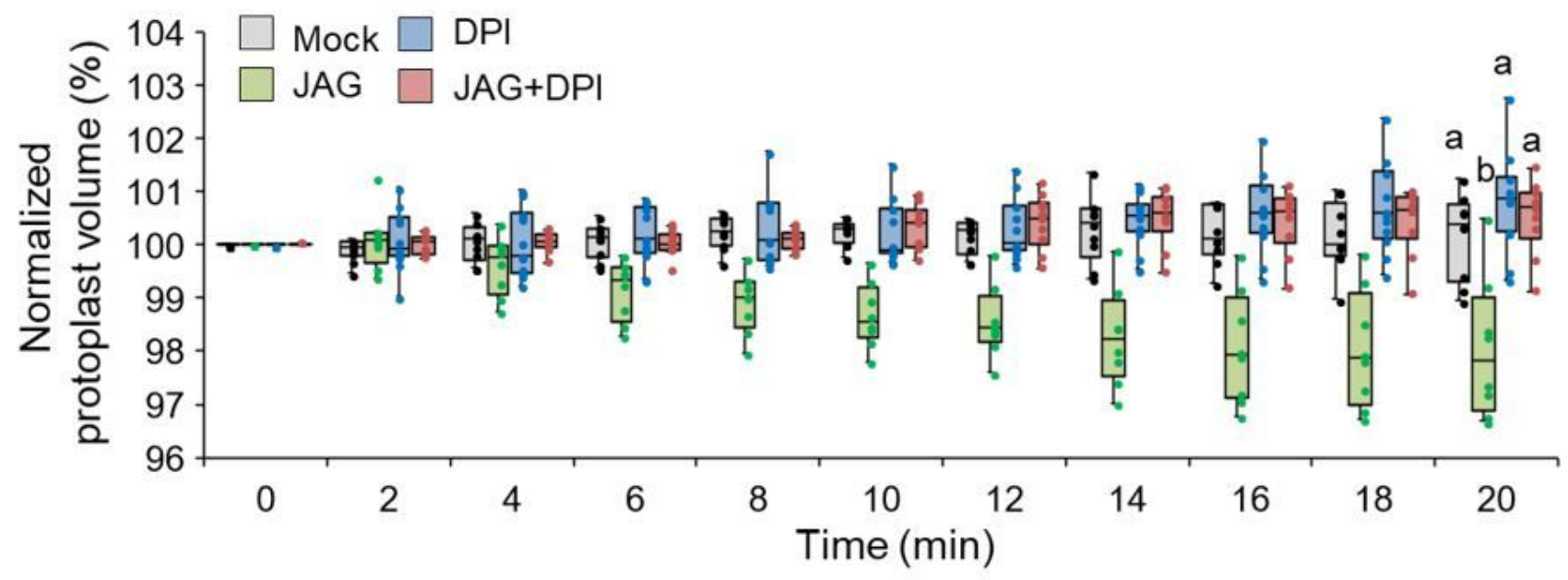

Figure 4

The effect of DPI on JAG induced ROS accumulation in tertiary extensor of $S$. saman. 
Effects of DPI (A and B) on JAG-induced cytosolic ROS accumulation (A) and cell shrinkage (B) in tertiary extensor protoplasts of $S$. saman. Protoplasts were preincubated for 30 min with $12.5 \mu \mathrm{M}$ DPI before adding $100 \mu \mathrm{M}$ JAG. All data points are shown as dot plots $(n=8-11)$. Different letters indicate significant differences (SNK post-hoc test, $\mathrm{P}<0.05$ ). All experiments were conducted during ZT 6-11. Four independent experiments were performed.

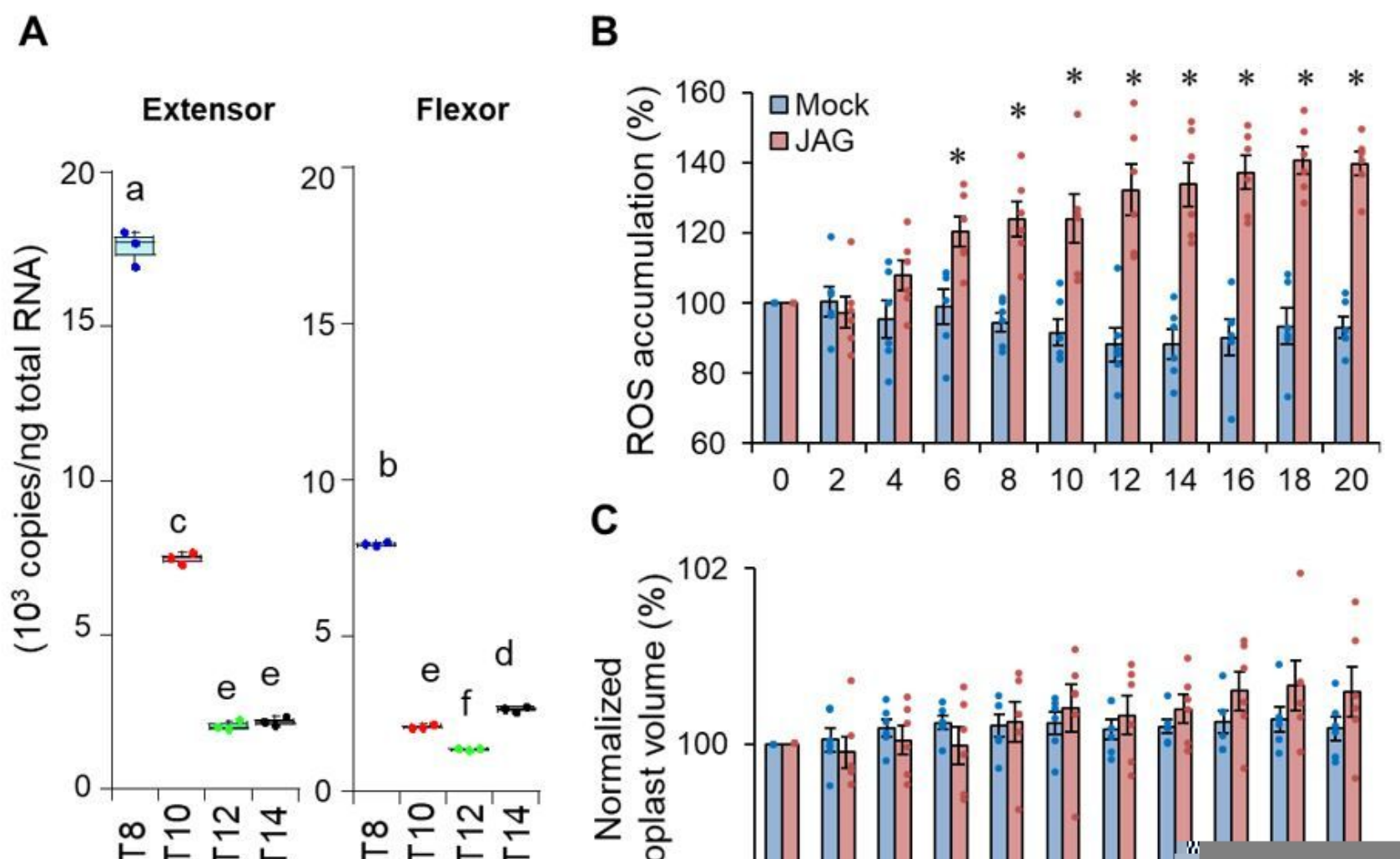

\section{Figure 5}

The effects of JAG on the extensor protoplasts that did not express SPORK2.

(A) The expression of SPORK2 gene during ZT8 -14 in extensor and flexor cells. All data points are shown as dot plots $(n=3)$. Different letters indicate significant differences (SNK post-hoc test, $P<0.05)$.

(B) and (C) Time course of JAG induced cytosolic ROS accumulation (B) and cell shrinkage (C) in tertiary extensor protoplasts of $S$. saman during ZT 14-18. The changes in normalized cytosolic fluorescence intensity of each protoplast were expressed by considering the negative control at each given points 
respectively. All data points are shown as dot plots $(n=6)$. Asterisks indicate significant differences ( ${ }^{\star} p<$ 0.05 ; $t$ test). Three independent experiments were performed.

\section{Supplementary Files}

This is a list of supplementary files associated with this preprint. Click to download.

- 07Feb2022SciRepSI.docx 